\title{
The role of community pharmacists in public health and public health related problems which they encounter
}

\author{
Çiğdem Samancı Tekin' (1) \\ 'Ömer Halisdemir University, Zübeyde Hanım School of Health, Public Health Nursing Department, Niğde, Turkey
}

ORCID IDs of the authors: C.S.T. 0000-0003-0895-1911

Cite this article as: Samanci Tekin, C. (2020). The role of community pharmacists in public health and public health related problems which they encounter. İstanbul Journal of Pharmacy, 50 (2), 142-148.

\begin{abstract}
Background and Aims: This study was conducted in order to identify the role of community pharmacists in public health and the public health related problems which are encountered.

Methods: In this cross-sectional study, 87 community pharmacists answered a questionnaire form about sociodemographic characteristics, public health counseling roles and barriers. The data was summarized as mean \pm standard deviation and percentage. Chi-square test was used to compare the categorical data.

Results: $93.1 \%$ of the community pharmacists considered that they had an active role in the protection of public health, while the percentage of those who thought they were able to realized it was $78.2 \%$. Limited authority $(63.2 \%)$, insufficient time and workload $(52.6 \%)$ were the leading causes of ineffectivity of the pharmacists in public health. The causes that prevented receiving consultancy services were shame $(64.4 \%)$, the education level of the client $(51.7 \%)$ and gender difference between the pharmacist and client ( $48.3 \%)$. The pharmacists thought that their professional reputation should be improved in order to improve their consulting role (35\%).

Conclusion: Although there are many occupational problems of pharmacists in Turkey, pharmacists voluntarily provide a consultacy service about many subjects for the protection of public health. Legal arrangements are needed to make pharmacies public health counseling centers.
\end{abstract}

Keywords: Pharmacists, Public health, Turkey, Pharmacy, Health promotion

\section{INTRODUCTION}

Pharmacists are the most accessible healthcare professionals in the society (World Health Organization, 1998; Eades, Ferguson, \& O'Carroll, 2011; Beshir \& Bt Hamzah, 2014). Community pharmacies are continuosly in communication with the society, and there is no need to make an appointment for receiving consultancy. Healthy individuals meet with health professionals as well as patients in pharmacies, so pharmacies have an important potential for public health (Anderson, Blenkinsopp, \& Armstrong, 2003; Erku et al., 2017). Due to these characteristics of them, they can provide solutions to the problems related to health protection and health improvement in public health services (Erku et al., 2017).

In addition to their pharmacological services, pharmacists also have consultancy and health education roles in health promotion programs. From this point of view, pharmacists play an active role in the provision of public health services (World Health Organization, 1998; Eades et al., 2011). Pharmaceutical public health has been defined as: "The application of pharmaceutical knowledge, skills and resources to the science and art of preventing disease, prolonging life, promoting, protecting and improving health for all through the organised efforts of society" (Walker, 2000). In many countries, such as England, America, Canada 
and Sweden, community pharmacists are active in public health issues, such as smoking cessation, diabetes monitoring, following up on cholesterol and blood pressure, folic acid and pregnancy, asthma, immunization, oral health, emergency hormonal contraception (Anderson et al., 2003; Saramunee et al., 2015; Agomo, Udoh, Kpokiri, \& Osuku-Opio, 2018).

Turkey ranks first and France second in terms of the number of pharmacies. According to the number of registered pharmacies in the country, the top five countries are Italy, France, Spain, Germany and Turkey. There were 34,870 pharmacists in Turkey and 25,896 of them were community pharmacists according to the data of 2018 (Turkish Pharmacists Association, 2018). Turkish Pharmacists' Association defined pharmaceutical public health competencies of pharmacists. These competences include providing information and advice on medications and other health products, health promotion and improvement, as well as identifying basic health needs, prevention and control of diseases, advising on promoting a healthy lifestyle (Turkish Pharmacists Association, 2015).

Emergency contraception was provided in community pharmacies in Turkey while diabetes and asthma management services were provided within the scope of My Counsellor Pharmacy Project. The public health services, such as blood pressure measurement, cholesterol measurement, glucose measurement, weight measurement, pregnancy testing, treatment of smoking cessation, hypertension management and vaccination services are not officially provided in pharmacies. The My Counsellor Pharmacy Project was launched in December 2014 by the Turkish Pharmacists Association. This project supports the continuous professional development of pharmacists. This project has been developed for pharmacists to receive health training regularly and train their counselees. At the present time the project is carried out as a pilot application in Turkey and it is aimed to spread the project across the nation in the future. The project is a step taken for the continuous training of pharmacists. Continuing education and professional development are not compulsory in Turkey while they are compulsory in many European countries. Therefore, this project is important for the professional development of pharmacists (Turkish Pharmacists Association, 2018).

This study was carried out to determine the current roles of community pharmacists in public health and their problems.

\section{MATERIALS AND METHODS}

This is a cross-sectional study. In Turkey there are 81 provinces and the city Niğde was chosen for the researcher to access easily. The study consisted of community pharmacists ( $n=100)$ in Niğde province of Turkey. The sample was not selected; it was aimed to reach the whole universe. 87 pharmacists were included in the study. Firstly, all pharmacies were informed about the study via the Chamber of Pharmacists in the Niğde. The pharmacies where pharmacists were not present, were continuously visited by the researcher until the pharmacists were met. A 17-question, questionnaire form was prepared by the researcher according to the literature, for the purpose of determining the characteristics of the pharmacists and pharmacies (age, sex, educational background, duration of pharmacy business, location of pharmacy, position of pharmacy, number of staff except the pharmacist, daily number of patients), ways of accessing information, characteristics of counselees, service provided by pharmacy, consultancy subjects and problems encountered. Questionnaire questions varied according to question types and they included questions that could be answered as yes/no/l have no idea, multiple-option questions for pharmacists and open-ended questions. The data was collected by using this questionnaire form applied by face to face interviews with the pharmacists who accepted to participate in the study.

The data were analyzed with SPSS 21.0 (version 21.0, SPSS, Inc, Chicago, IL, 2012). The data were transferred to the computer and summarized as mean \pm standard deviation and percentage. Chi-square test was used to compare categorical data (used to compare qualitative variables such as pharmacists' active role in public health, providing counselling and having adequate information about counselling with qualitative variables such as age, sex, occupational year, expertise, location of pharmacy, number of staff and number of patients). $p<0.05$ was accepted as statistically significant.

Ethical approval: The study was carried out with the approval of Niğde Ömer Halisdemir University Ethics Committee (No:2018/11-05). Permission was also obtained from the Niğde Chamber of Pharmacists.

\section{RESULTS}

In this study, 87 of 100 pharmacies in the Niğde province of Turkey were included. $42.5 \%$ of the pharmacists were female. According to the Turkish Statistics for the year 2018, the ratio of female pharmacists in Niğde was lower than the ratio of female pharmacists in Turkey (Turkish Pharmacists Association 2018). The mean age was $44.3 \pm 16.0$ years. $20.7 \%$ of the pharmacists were 65 years old or older. 13.8\% of them were senior pharmacists. Their mean working year as a pharmacist was $19.0 \pm 14.4$ years. $55.2 \%$ of the pharmacies were located in the city center. $32.2 \%$ of the pharmacies were close to a hospital; $33.3 \%$ were close to a family health center; $34.5 \%$ of them were in the center of province. $56.3 \%$ of the pharmacies had 2 or more personnel except pharmacists. 52.9\% of the pharmacies had 51-100 patients a day (Table 1).

More than half of the pharmacists (55.2\%) thought that the public health course in the University education was not sufficient. The pharmacists reached up-to-date information on health through the Internet (87.4\%), journals-books (58.6\%) and social media (54\%). Nearly half of the pharmacists (49.4\%) stated that they obtained information from their colleagues. 75.9\% of the pharmacists stated that they could use the internet effectively. While $93.1 \%$ of the pharmacists believed that they played an active role in protecting public health, one fifth of them (21.8\%) thought that they were not active in protecting public health, considering their present condition. It was determined that there was no significant difference between the pharmacists in the city center and in the countryside in terms of being active in public health $\left(x^{2}=0.104, p=0.748\right)$. The pharmacists who were near the hospital thought that they were more active $\left(x^{2}=7.741, p=0.021\right)$. 


\section{Table 1. Sociodemographic characteristics of pharmacists and pharmacy locations.}

\begin{tabular}{|c|c|c|}
\hline Sociodemographic Characteristics & $\mathbf{N}$ & $\%$ \\
\hline \multicolumn{3}{|l|}{ Gender } \\
\hline Female & 37 & 42.5 \\
\hline Male & 50 & 57.5 \\
\hline \multicolumn{3}{|l|}{ Age } \\
\hline $25-40$ & 47 & 54.0 \\
\hline 41-55 & 14 & 16.1 \\
\hline $56-75$ & 26 & 29.9 \\
\hline \multicolumn{3}{|l|}{ Education Level } \\
\hline Undergraduate & 75 & 86.2 \\
\hline Master & 12 & 13.8 \\
\hline $\mathrm{PhD}$ & - & - \\
\hline \multicolumn{3}{|l|}{ Working experience as a pharmacist } \\
\hline $1-10$ years & 33 & 37.9 \\
\hline $11-20$ years & 21 & 24.1 \\
\hline $21-30$ years & 10 & 11.5 \\
\hline 31 years or longer & 23 & 26.4 \\
\hline \multicolumn{3}{|l|}{ Location of the Pharmacy } \\
\hline City Center & 48 & 55.2 \\
\hline District & 34 & 39.1 \\
\hline Town & 5 & 5.7 \\
\hline \multicolumn{3}{|l|}{ Location of the Pharmacy } \\
\hline Near a Hospital & 28 & 32.2 \\
\hline Near a Family Health Center & 29 & 33.3 \\
\hline On a Central Street & 30 & 34.5 \\
\hline \multicolumn{3}{|l|}{ Number of Personnel in Pharmacy } \\
\hline $0-2$ & 38 & 43.7 \\
\hline 3 or more & & \\
\hline \multicolumn{3}{|l|}{ Daily Patient Number } \\
\hline 50 or below & 33 & 37.9 \\
\hline $51-100$ & 46 & 52.9 \\
\hline 101 or above & 8 & 9.2 \\
\hline
\end{tabular}

A question was addressed to the pharmacists who thought that they were not active in public health, containing their reasons for not being active, as well as multiple options and open-ended expression. Accordingly the health system, the limitation of authority (63.2\%), insufficent time and workload (52.6\%) were among the main reasons for the ineffective role of the pharmacists in public health (Table 2).

Table 2. Reasons of "Pharmacists' Inactive in Public Health"*

\begin{tabular}{|lcc|}
\hline Reason & N & \% \\
\hline Health system & 12 & 63.2 \\
Authority limitation & 12 & 63.2 \\
Insufficient time & 10 & 52.6 \\
High workload & 10 & 52.6 \\
Unsuitable place & 6 & 31.6 \\
Personnel inadequacy & 5 & 26.3 \\
Other & 5 & 26.3 \\
\hline *Multiple choices were marked, N: Number of respondents \\
\hline
\end{tabular}

$77 \%$ of the beneficiaries of pharmacy services were the individuals with low educational and socioeconomic status. The question of "In your opinion, what are the first three occupational groups in which the community receives counseling on health-related issues?" was answered as pharmacists (50.6\%), physicians (40.2\%), and health personnel (55.2\%). In pharmacies, prescription medicine (98.9\%), counseling (34.5\%) and non-prescription medicine (21.8\%) services were provided, respectively. $13.8 \%$ of the pharmacists stated that consultancy service increased; $54 \%$ of them stated that consultancy service had not changed; \%14.9 of them stated that it decreased in the last 6 months.

The obstacles for receiving counseling services from pharmacists are presented in Table 3. Feeling ashamed by the clients (64.4\%), their educational status (51.7\%), gender difference between a pharmacist and a client (48.3\%) were the obstracles determined, respectively (Table 3). Nowadays, the internet has an important place in our lives. The rate of pharmacists who thought that the widespread use of the internet affected the pharmacists' counseling roles was $69.4 \%$. The pharmacists thought that most of the clients came to the pharmacy with the wrong information because of increased internet usage (71.2\%). While, for the pharmacists, the widespread use of the internet increased their access to health information (35.6\%) (Table 4). 47.1\% of the pharmacists made open-ended suggestions for the purpose of increasing counselling services. Most of them answered as increasing the professional reputation

\section{Table 3. Obstacles for "Receiving Consultancy} Services"*

\begin{tabular}{|lcc|}
\hline Obstacle & N & \% \\
\hline Client's educational status & 45 & 51.7 \\
Gender difference & 42 & 48.3 \\
Shame & 56 & 64.4 \\
Being crowded of pharmacy & 21 & 24.1 \\
Inability to communicate appropriately & 17 & 19.5 \\
Busying of the pharmacist & 19 & 21.8 \\
Other & 7 & 8.0 \\
\hline
\end{tabular}

*Multiple choices were marked, N: Number of respondents

\section{Table 4. Effect of internet usage on pharmacists' counseling roles*}

\begin{tabular}{|lcc|}
\hline Variable & N & \% \\
\hline My counseling role decreased & 20 & 33.9 \\
My counseling role increased & 10 & 16.9 \\
My Access to information increased & 21 & 35.6 \\
Clients came with wrong information & 42 & 71.2 \\
Clients are informed & 9 & 15.3 \\
Other & 2 & 3.4 \\
\hline *Multiple choices were marked, N: Number of respondents \\
\hline
\end{tabular}


Table 5. Pharmacists' counselling rate and their sufficiency in counselling.

\begin{tabular}{|c|c|c|c|c|}
\hline \multirow[b]{2}{*}{ Consultancy Issues } & \multirow[b]{2}{*}{$\mathrm{N}$} & \multirow[b]{2}{*}{$\%$} & \multicolumn{2}{|c|}{ Knowledge Sufficient } \\
\hline & & & $\mathbf{N}$ & $\%$ \\
\hline Smoking cessation & & & 70 & 80.5 \\
\hline Yes & 75 & 86.2 & & \\
\hline No & 12 & 13.8 & & \\
\hline Alcohol cessation & & & 66 & 75.9 \\
\hline Yes & 33 & 37.9 & & \\
\hline No & 54 & 62.1 & & \\
\hline Substance Addiction & & & 62 & 71.3 \\
\hline Yes & 20 & 23.0 & & \\
\hline No & 67 & 77.0 & & \\
\hline Healthy Nutrition & & & 69 & 79.3 \\
\hline Yes & 64 & 73.6 & & \\
\hline No & 23 & 26.4 & & \\
\hline Weight Control & & & 69 & 79.3 \\
\hline Yes & 57 & 65.5 & & \\
\hline No & 30 & 34.5 & & \\
\hline Physical Activity & & & 67 & 77.0 \\
\hline Yes & 50 & 57.5 & & \\
\hline No & 37 & 42.5 & & \\
\hline Communicable Diseases & & & 61 & 70.1 \\
\hline Yes & 49 & 56.3 & & \\
\hline No & 38 & 43.7 & & \\
\hline Vacines & & & 64 & 73.6 \\
\hline Yes & 55 & 63.2 & & \\
\hline No & 32 & 36.8 & & \\
\hline Hypertension & & & 75 & 86.2 \\
\hline Yes & 77 & 88.5 & & \\
\hline No & 10 & 11.5 & & \\
\hline Diabetes & & & 73 & 83.9 \\
\hline Yes & 76 & 87.4 & & \\
\hline No & 11 & 12.6 & & \\
\hline Hyperlipidemia & & & 75 & 86.2 \\
\hline Yes & 72 & 82.8 & & \\
\hline No & 15 & 17.2 & & \\
\hline Asthma-COPD* & & & 75 & 86.2 \\
\hline Yes & 74 & 85.1 & & \\
\hline No & 13 & 14.9 & & \\
\hline Rational Drug Use & & & 68 & 78.2 \\
\hline Yes & 71 & 81.6 & & \\
\hline No & 16 & 18.4 & & \\
\hline Emergency Contraception & & & 63 & 72.4 \\
\hline Yes & 36 & 41.4 & & \\
\hline No & 51 & 58.6 & & \\
\hline Family Planning Methods & & & 68 & 78.2 \\
\hline Yes & 42 & 48.3 & & \\
\hline No & 45 & 51.7 & & \\
\hline Sexually Transmissible Diseases & & & 69 & 79.3 \\
\hline Yes & 34 & 39.1 & & \\
\hline No & 53 & 60.9 & & \\
\hline Suicide Risk & & & 54 & 62.1 \\
\hline Yes & 11 & 12.6 & & \\
\hline No & 76 & 87.4 & & \\
\hline Osteoporosis & & & 68 & 78.2 \\
\hline Yes & 65 & 74.7 & & \\
\hline No & 22 & 25.3 & & \\
\hline Total & 87 & 100 & & \\
\hline
\end{tabular}


Table 6. Issues in which pharmacists provide counselling according to their sex.

\begin{tabular}{|c|c|c|c|c|c|c|c|c|c|c|}
\hline \multirow[b]{3}{*}{ Issues } & \multicolumn{4}{|c|}{ Female Pharmacists } & \multicolumn{4}{|c|}{ Male Pharmacists } & \multirow[b]{3}{*}{$\mathrm{X}^{2}$} & \multirow[b]{3}{*}{$\mathbf{P}$} \\
\hline & \multicolumn{2}{|c|}{ Yes } & \multicolumn{2}{|c|}{ No } & \multicolumn{2}{|c|}{ Yes } & \multicolumn{2}{|c|}{ No } & & \\
\hline & $\mathbf{N}$ & $\%$ & $\mathrm{~N}$ & $\%$ & $\mathrm{~N}$ & $\%$ & $\mathrm{~N}$ & $\%$ & & \\
\hline Smoking cessation & 32 & 86.5 & 5 & 13.5 & 43 & 86.0 & 7 & 14.0 & 0.004 & 0.948 \\
\hline Alcohol cessation & 7 & 19.0 & 37 & 81.0 & 26 & 52.0 & 24 & 48.0 & 9.884 & 0.002 \\
\hline Substance Addiction & 6 & 16.2 & 31 & 83.8 & 14 & 28.0 & 36 & 72.0 & 1.668 & 0.197 \\
\hline Healthy Nutrition & 32 & 86.5 & 5 & 13.5 & 32 & 64.0 & 18 & 32.0 & 5.529 & 0.019 \\
\hline Weight Control & 28 & 75.7 & 9 & 24.3 & 29 & 58.0 & 21 & 42.0 & 2.941 & 0.086 \\
\hline Physical Activity & 22 & 59.5 & 15 & 40.5 & 28 & 56.0 & 22 & 44.0 & 0.104 & 0.747 \\
\hline Communicable Diseases & 19 & 51.3 & 18 & 48.7 & 30 & 60.0 & 20 & 40.0 & 0.647 & 0.421 \\
\hline Vaccines & 21 & 56.8 & 16 & 43.2 & 34 & 68.0 & 16 & 32.0 & 1.156 & 0.282 \\
\hline Hypertension & 34 & 91.9 & 3 & 7.1 & 43 & 86.0 & 7 & 14.0 & 0.726 & 0.394 \\
\hline Diabetes & 33 & 89.2 & 4 & 10.8 & 43 & 86.0 & 7 & 14.0 & 0.196 & 0.658 \\
\hline Hyperlipidemia & 32 & 86.5 & 5 & 13.5 & 40 & 80.0 & 10 & 20.0 & 0.627 & 0.428 \\
\hline Asthma-COPD* & 33 & 89.2 & 4 & 10.8 & 41 & 82.0 & 9 & 18.0 & 0.865 & 0.352 \\
\hline Rational Drug Use Emergency & 31 & 83.8 & 6 & 16.2 & 40 & 80.0 & 10 & 20.0 & 0.203 & 0.652 \\
\hline Contraception & 21 & 56.8 & 16 & 43.2 & 15 & 30.0 & 35 & 70.0 & 6.276 & 0.012 \\
\hline Family Planning Methods & 21 & 56.8 & 16 & 43.2 & 21 & 42.0 & 29 & 58.0 & 1.854 & 0.173 \\
\hline Sexually Transmissible Diseases & 12 & 32.4 & 25 & 67.6 & 22 & 44.0 & 28 & 56.0 & 1.195 & 0.274 \\
\hline Suicide Risk & 4 & 10.8 & 33 & 89.2 & 7 & 14.0 & 43 & 86.0 & 0.196 & 0.658 \\
\hline Osteoporosis & 33 & 89.2 & 4 & 10.8 & 32 & 64.0 & 18 & 32.0 & 7.141 & 0.008 \\
\hline
\end{tabular}

(35\%) and providing informative regular meetings and inservice training (33.3\%). In addition, the following recommendations were given: not seeing pharmacies as a commercial establishment, paying hospital admissions in hospitals, reducing commercial concerns of pharmacists, reducing pharmaceutical procedures, introducing pharmacy, increasing professional unity, paying wages for counseling services, availability of a pharmacist in a pharmacy, communication of pharmacists with patients, compliance of pharmacists with the ethical rules, the inspection of internet products, improving pharmacists by themselves, increasing the authorities of pharmacists, establishing an official web site where pharmacists can benefit about counselling issues.

Several consultancy services were given about many public health issues in the pharmacies (Table 5). The main issues were related to hypertension (88.5\%), diabetes (87.4\%) and smoking cessation (86.2\%). The issues in which the pharmacist thought that they had insufficient information, were suicide risk (37.9\%), infectious diseases (29.9\%) and substance addiction (28.7\%).

The state of receiving counseling was compared with variables such as age, gender, occupational year, speciality, location of pharmacy, number of personnel and number of patients. According to the location of pharmacy; the pharmacists in the city center provided more counseling for physical activity $\left(x^{2}=10.457, p=0.005\right)$ and emergency contraception $\left(X^{2}=10.009\right.$, $p=0.007$ ), compared to the pharmacists in the countryside. Also, significant differences were found in some issues in which counseling was provided according to the pharmacist's gender. Accordingly, the female pharmacists provide more counseling about healthy nutrition, emergency contraception and osteoporosis than the male pharmacists, whereas, the male pharmacists provide more counseling about alcohol cessation compared to the female pharmacists (Table 6).

The male pharmacists thought that they had more adequate information about smoking cessation $\left(x^{2}=6.806, p=0.009\right)$, alcohol cessation $\left(x^{2}=4.252, p=0.039\right)$, drug addiction $\left(x^{2}=4.381\right.$, $p=0.036)$ and rational drug use $\left(x^{2}=4.232, p=0.040\right)$ than the female pharmacists.

\section{DISCUSSION}

When mean numbers of personnel working in a pharmacy are compared between European countries, the pharmacies in Turkey have the lowest mean number of employees as 3 while the pharmacies in Denmark have the highest mean number of employees as 14 (Turkish Pharmacists Association, 2018). Similarly, more than half of the pharmacists enrolled in our study had 2 or more personnel.

More than three quarters of the pharmacists use the Internet effectively (75.9\%). In contrast to our study, a study performed in the United Kingdom in 2017 identified the reluctancy of the pharmacists to use technology and social media as one of the obstacles in public health (Agomo, Portlock, \& Ogunleye, 2017).

More than one-fifth of the pharmacists thought that they did not have an active role in the protection of public health due to the health system, authority limitation, insufficient time and high workload. In a study conducted on pharmacists, similar results to our findings were obtained, such as the inability to allocate adequate time to patients/inability to give satisfactory answers to patients, providing a consultancy service for the Social Security Institution, frustration, lack of time for selfimprovement (Gülpınar, Uzun, \& Yalım, 2015). In another study 
conducted in the United Kingdom, the health system and time limitation were defined as an obstacle for pharmacists to carry out public health roles (Agomo et al., 2017). More than three quarters of the beneficiaries of pharmacy services have low education and income levels. The level of education and health literacy are related concepts (Balcık, Taskaya, \& Sahin, 2014). This result shows that the counseling service is necessary on its own and pharmacies are a good opportunity for counseling.

Although the occupational group was asked, the third occupation group which was consulted on health issues was determined as neighbour, friend, television, internet and herbalist by $30 \%$ of the pharmacists. In a study, the rate of using traditional medical methods was found to be $65.8 \%$ (Oral, Ozturk, Balcı, \& Sevinc, 2016). This result shows that traditional practices still play an important role in health. The most important factors affecting the counseling situation were shame, education, and gender. This situation can be explained by the cultural characteristics of Turkish society except the lack of education.

As is the case in different areas, especially in the field of health, the internet which is used effectively and widely can cause undesired results when not being used carefully (Gorkemli, 2017). Unhelpful or wrong advices found on the Internet and social media may lead to important health problems (Prasad, 2013). The fact that the clients came to the pharmacy with wrong information showed that they did not use the internet resources rationally.

The pharmacists thought that their professional reputation should be increased. Similarly, the pharmacists thought that their professional reputation decreased in another study conducted with the pharmacists (Gülpınar et al., 2015).

The role of community pharmacists as an active contributor to public health in addition to their traditional role in medication is recognized around the World (Eades et al., 2011). Although it is officially limited, pharmacists consult on numerous public health issues such as hypertension, diabetes, smoking cessation, hyperlipidemia, asthma- Chronic Obstructive Pulmonary Disease (COPD) and weight control. While, the counseling for alcohol abuse, substance abuse and suicide risk were least provided. In contrast to our study, it was found that a small number of pharmacies provided counseling services on issues, such as smoking cessation, weight management, hypertension screening, diabetes, dyslipidemia in a study conducted in Ethiopia. The counseling for screening of infectious diseases, sexually transmitted diseases, emergency contraception methods and alcohol dependence were most provided (Erku \& Mersha, 2017). This result shows that each country has different public health problems and needs for counseling.

The subjects in which the pharmacists thought that they had insufficient knowledge were suicide risk, communicable diseases and substance abuse. Professional development is not compulsory for pharmacists in Turkey. In order to meet the educational needs systematically, professional development should be made compulsory.

The fact that the pharmacists in the city center provided more counseling for physical activity than the pharmacists in the countryside might be associated with the fact that people in cities lead a more sedentary life and thus, need physical activities more. On the other hand, the fact that counseling for emergency contraceptive methods was provided more in the city center might be associated with the fact that urban women want fewer children due to reasons, such as being more aware of the presence of emergency contraceptive methods, greater participation in the labor force and higher educational level. The female pharmacists mainly provided counseling for issues concerning women and affecting their health, such as healthy nutrition, emergency contraception and osteoporosis. On the other hand, the male pharmacists mainly provided counseling for alcohol cessation, which is encountered in men. According to these results, it is possible to conclude that the counselees consult with fellow pharmacists for some issues.

Keeping pharmacists away from bureaucratic obstacles in Turkey, improving their professional reputation, preventing pharmacies from being perceived as trading houses, providing financial support to pharmacies' public health services as in the United States and fulfilling their training needs systematically, are important. According to these findings, it can be suggested for the Turkish Union of Pharmacists to conduct studies in order to determine problems faced by pharmacies across Turkey and to lead in establishing a system for continuous training of pharmacists. Public health services which are provided voluntarily in pharmacies in Turkey should be made formal via laws.

\section{CONCLUSION}

In conclusion, there were no studies within this scope in Turkey before this study. In this study, the current situation of the pharmacists in Turkey and their problems in terms of public health were identified. Although pharmacists in Turkey face professional problems (such as bureaucratic obstacles, work load, limitation of authority), it is possible to state that they usually play a voluntarily active role in protecting and developing public health. There is a need for more scientific studies in order to make the active participation of pharmacists in public health seem visible and to enhance it.

Peer-review: Externally peer-reviewed.

Author Contributions: Conception/Design of Study- Ç.S.T.; Data Acquisition- Ç.S.T.; Data Analysis/Interpretation- Ç.S.T.; Drafting Manuscript- Ç.S.T.; Critical Revision of Manuscript- Ç.S.T.; Final Approval and Accountability-G Ç.S.T.; Technical or Material Support- Ç.S.T.; Supervision- Ç.S.T.

Conflict of Interest: The author has no conflict of interest to declare.

Financial Disclosure: Author declared no financial support.

\section{REFERENCES}

- $\quad$ Agomo, C. O., Portlock, J., \& Ogunleye, J. (2017). Barriers in the public health role of community pharmacists: a qualitative study. Journal of Pharmaceutical Health Services Research, 8, 261-267.

- $\quad$ Agomo, C. O., Udoh, A., Kpokiri, E., \& Osuku-Opio, J. (2018). Community pharmacists' contribution to public health: assessing the global evidence base. Clinical Pharmacist, 10(4), 1-34. 
- $\quad$ Anderson, C., Blenkinsopp, A., \& Armstrong, M. (2003). The contribution of community pharmacy to improving the public's health. Report 1, Evidence from the peer-reviewed literature 1990-2001.

- Balcık, P. Y., Taskaya, S., \& Sahin, B. (2014). Sağlık okur-yazarlığı [Health Literacy]. TAF Preventive Medicine Bulletin, 13(4), 321-326.

- Beshir, S. A., \& Bt Hamzah, N. H. (2014). Health promotion and health education: perception, barriers and standard of practices of community pharmacists. International Journal of Health Promotion and Education, 52(4), 174-180.

- Eades, C. E., Ferguson, J. S., \& O'Carroll, R. E. (2011). Public health in community pharmacy: a systematic review of pharmacist and consumer views. BMC public health, 11(1), 582.

- Erku, D. A., \& Mersha, A. G. (2017). Involvement of community pharmacists in public health priorities: A multi-center descriptive survey in Ethiopia. PLoS One, 12(7),1-11.

- Erku, D. A., Belachew, S. A., Mekuria, A. B., Haile, K. T., Gebresillassie, B. M., Tegegn, H. G., \& Ayele, A. A. (2017). The role of community pharmacists in patient counseling and health education: a survey of their knowledge and level of involvement in relation to type 2 diabetes mellitus. Integrated pharmacy research \& practice, $6,137-143$

- Gorkemli, N. (2017). A study on Internet usage in health communıcatıon. Turkish Online Journal of Design Art and Communication, 7(1), 122-138.

- Gülpınar, G., Uzun, M. B., \& Yalım, N. Y. (2015). Sosyal Güvenlik Kurumu uygulamalarının serbest eczacıların iş doyumu üzerine etkisi: Kalitatif bir çalışma [The effects of Social Security Institution implementations on community pharmacists' job satisfaction: a qualitative study]. Turkish Journal of Bioethics, 2(1), 36-46.
Oral, B., Ozturk, A., Balcı, E., \& Sevinc, N. (2016). State of opinions and use about traditional/alternative medicine who applied to family health center. TAF Preventive Medicine Bulletin, 15(2), 75-82. Prasad, B. (2013). Social media, health care, and social networking. Gastrointestinal endoscopy, 77(3), 492-495.

- Saramunee, K., Krska, J., Mackridge, A., Richards, J., Suttajit, S., \& Phillips-Howard, P. (2015). General public's views on pharmacy public health services: current situation and opportunities in the future. Public Health, 129(6), 705-715.

- Turkish Pharmacists Association. (2015). Turkish pharmacists basic national competence framework [Türk eczacıları temel ulusal yetkinlik çerçevesi]. Retrieved from http://www.rehbereczanem. com/ulusal_yetkinlik.pdf Accessed 12.07.2019.

Turkish Pharmacists Association. (2018). Health, medicine and pharmacy statistics yearbook 2018. [ Sağlık, Ilaç ve Eczacılık İstatistikleri Yıllığı 2018]. Retrieved from https://dergi.tebeczane.net/public_html/kitaplar/seiy_2018/html5/index. html?\&locale=TRK Accessed 08.02.2019

- Walker, R. (2000). Pharmaceutical public health: the end of pharmaceutical care. Pharmaceutical Journal, 264(7085), 340-341.

- World Health Organization. (1998). The Role of the pharmacist in self-care and self-medication: report of the 4th WHO Consultative Group on the Role of the Pharmacist, The Hague, The Netherlands, 26-28 August 1998 (No. WHO/DAP/98.13). World Health Organization. 